\title{
Rural Voices on Quality of Service Delivery in Community-Based Health Planning and Services in the Wassa-Amenfi West District, Ghana
}

\author{
${ }^{1}$ David Naya Zuure*, ${ }^{2}$ Sarah Nsowah and ${ }^{3} J a m e s$ Gbandan Konzabre \\ ${ }^{1}$ University of Education, Winneba, Ghana, \\ ${ }^{2}$ University of Cape Coast, Ghana \\ ${ }^{3}$ St. John Bosco College of Education, Ghana
}

*Corresponding Author: davidonzuurich01@yahoo.com

\begin{abstract}
The study sought to establish respondents' views on the attitude of health care providers, perceptions of the quality of medical services provided and indications on the future use of CHPS compound in the Wassa-Amenfi West District. The study employed the cross-sectional survey design within the quantitative research paradigm. Questionnaire was administered to one hundred and fifty community members and analysis was done through frequencies and percentages. The study concluded that respondents had positive views on the attitude of health service providers in the CHPS compound. They were also satisfied with the quality of service delivery at the CHPS compound. Respondents were willing to visit and recommend family members and friends to the facility in the future to access healthcare. It was therefore recommended that medicines and health information should be made available at the compound to enhance quality health delivery at the grass root.
\end{abstract}

Keywords: Health, Attitude, Quality, Delivery, CHPS, Satisfaction

\section{Introduction}

The Sustainable Development Goal Three (SDG3) requires among others, that by 2030, members states of the United Nations should reduce global maternal mortality ratio to less than 70 per 1,000 live births, end preventable deaths of newborns and children under 5 years of age, reduce by one third premature mortality from non-communicable diseases, halve the number of global deaths and injuries from road traffic accidents reduced, ensure universal access to sexual and reproductive health-care services, achieve universal health coverage including financial risk protection, improve access to safe, effective, quality and affordable essential medicines (United Nations Development Program, 2017). Meanwhile, in most developing societies, accessing adequate and satisfactory health care services is based on ability and willingness to pay rather than need (Esteban, 2017).

Again, ensuring healthy lives for all is important for building prosperous societies and at the same time a critical human right concern (Zuure, 2020). Promoting good health for individuals ensures that they are able to perform well in every aspect of their lives. Accordingly, Ghana over the years has implemented various policies and programs aimed at providing affordable and quality healthcare services for its citizens (Escribano-Ferrer, Cluzeau, Cutler, Akufo, and Chalkidou (2016).

A healthy population according to Duggirala, Rajendran, and Anantharaman (2008), when characterized by balanced birth and death rates, and a low incidence of disease, is very essential for the development and prosperity of a nation. Therefore, concerns of nations must be on ensuring quality healthcare that is successful in appropriately managing the diseases of people and at the same time ensuring accessible and affordable health services.

Among many policies adopted by the Ghana Health Service (GHS) to ensure health care for people in the country, especially those in the rural and deprived areas, is a three-tier level of service provision within the district: the District (hospital) level, the SubDistrict (health centre) level, and Community-Based level (GHS, 2005). Community-Based Health Planning Services (CHPS) compounds serve as the first point of call for basic treatment of minor 
ailment, family planning, antenatal care, delivery and postnatal care, child welfare clinic and immunization, among others at the community level. A CHPS compound is managed by a resident Community Health Officer ( $\mathrm{CHO}$ ) and assisted by volunteers and community members (GHS, 2005).

The CHPS strategy implemented in Ghana is indeed essential in enhancing community involvement and ownership of primary healthcare interventions towards achieving Universal Health Coverage (UHC). For the limited healthcare resources to be allocated effectively, it would be essential for healthcare providers to identify patients' priority dimensions and improve these dimensions for patients' satisfaction. However, since the introduction of the CHPS compounds in Ghana in 1999, little is known about recipients' attitude on service providers and their satisfaction with the quality of services delivery which are two important components of healthcare (Van den Broek \& Graham, 2009). This study, therefore, examined views of people on quality of service delivery and attitude toward healthcare providers in CHPS compound in the Wassa-Amenfi West District. The study was guided by the following research questions:

1. What are rural community members' perceptions on the attitude of health care providers in CHPS compounds in the WassaAmenfi West District?

2. What perceptions do rural community members have on the quality of medical services provided by CHPS Compound in Wassa-Amenfi West District?"

3. What are the opinions of rural community members in the Wassa-Amenfi West District on the future use of CHPS compounds?

\section{Literature Review}

This part reviewed the Equity Theory, which provided basis for the study. It also covered the empirical review of works on patients' satisfaction of healthcare service delivery as well the CHPS approach to healthcare delivery in Ghana.

\section{The Equity Theory}

This theory contends that, satisfaction exists when consumers estimate the ratio of input and output to be fair (Swan \& Oliver, 1989). According to this theory, people will feel equitably treated if in their minds the ratio of their outcomes to inputs is fair (Oliver \& DeSarbo, 1988). Whether a person feels equitably treated or not may depend on various factors including the price paid, the benefits received, the time and effort expended during the transaction and the experience of previous transactions (Woodruff, Ernest, \& Jenkins, 1983).

Relating this to quality healthcare delivery, the Equity theory submits that patients compare perceived input-output in the process of accessing health services. If the patients on one hand feel they have obtained less gain compared to what they have put in, they will become dissatisfied with the services from the health facility (Reisinger \& Turner, 1997). On the other hand, if the patients feel what they have put in to access healthcare service is fairly equal or even greater, then they will be satisfied. Therefore, satisfaction is, "a mental state of being adequately or inadequately rewarded" (Moutinho, 1987).

According to the Equity theory, satisfaction is regarded as a relative conclusion that looks at both the qualities and benefits attained through a transaction as well as the efforts and costs borne by a consumer in the transaction. In a study by Fisk and Coney (1982), they found that consumers were less satisfied and had a less positive attitude toward a company when they heard that other customers received a better price deal and better service than them. This means, the perceptions of these consumers of equitable treatment by the company translated into satisfaction judgments which informed their subsequent transactions decisions. The investment of public funds into establishing and running the CHPS compounds, therefore, requires that, measures are put in place so that the output form the facilities would meet the expectations and satisfaction of the community members who patronize them as to meet the position of the Equity theory.

\section{Determinants of Patient Satisfaction}

Satisfaction is an essential measure of patients' perception of healthcare quality (Al-Abri and AlBalushi, 2014). There have been studies geared towards understanding the factors associated with patients' satisfaction with healthcare services. Kathryn, David and Susan (2004) cite Kaneet et al. (1997) who state that measuring satisfaction should include elements of technical, interpersonal, social and moral aspects of care. Research outcomes on patients' satisfaction show many common features that influence the overall satisfaction in both developed and developing countries (Iftikhar et al, 2011). Similarly, Nguyen, Anota, Brédart, Monnier, 
Bosset and Mercier (2014) and Jenkinson, Coulter, Bruster, Richards and Chandola (2012) view that age and health status are the two major determinants of healthcare satisfaction. In Pakistan, Shou-Hisa, Ming-Ching and Tung-uang (2003) found that patient characteristics such as age, gender and education level slightly influenced patient's satisfaction but the health status of the patients is an important predictor of a patient's overall satisfaction with healthcare service. Al-Abri and AlBalushi (2014) discovered that the nurses' courtesy, respect, careful listening and easy access of care are major drivers of patients' satisfaction with healthcare services.

\section{Community-Based Health Planning and Services (CHPS) in Ghana}

Ghana has implemented and undergone a number of health care reforms. These reforms have been targeted at ensuring easy access to primary healthcare services. Nonetheless, accessibility remains a challenge, particularly in poor, marginalized rural settings (Yeleduor, 2012). The introduction of the Community-Based Health Planning and Services (CHPS) in Ghana has been the Government of Ghana's flagship initiative to making healthcare physically accessible to all (Yeleduor, 2012).

In an effort to provide Community-based 'close-toclient" doorstep healthcare services, the Ghana Ministry of Health and the Ghana Health Service replicated an experimental local-level healthcare provision initiative (Navrongo Community Health and Family Planning Project - CHFP) in three pilot districts namely Nkwanta, Birim North and AsebuAbura-Kwamankese. The CHPS initiative is therefore a national strategy for reorienting and relocating primary health care from sub-district health centres to convenient community locations (Yeleduor, 2012).

The strategic policy of the Ghana Health Service is to have a three-tier (district hospitals, sub-district health centres and CHPS at the community level) healthcare delivery service within a district. CHPS catchments usually cover a population of between 3,000 to 4,500 people, manned by resident Community Health Officer, assisted by the community structures and volunteer systems.

The focus of the CHPS initiative is to achieve three important objectives;

1. To improve equity in access to basic health services; the mal-distribution and problems associated with geographical and financial access means that new ways of working are required to deal with the basic ailments that plague the poor. The CHPS strategic response takes into consideration working with households and communities to ensure that all barriers to access at the local levels are removed.

2. To improve efficiency and responsiveness to client needs; community-based service provision can only be effective if services are efficiently delivered and are responsive to clients' needs. This can be ensured through increasing accountability and performance of health providers on quality, responsiveness and efficiency to the communities.

3. To improve inter-sectorial collaboration and partnership in service delivery; this will require strengthening the role of the community, civil society and communitybased organizations to support strategy implementation, client access to services and protect the right of clients to quality health services.

This is aimed at providing good healthcare to citizens through quality services delivery at CHPS facilities particularly in rural communities which are highly dependent on such services.

\section{Patient Satisfaction and Quality Healthcare in the Context of Ghana}

Research evidence suggests mixed perceptions on client satisfaction with provision of healthcare services in Ghana (Turkson, 2009). Trust and confidence in the health service is often undermined by frequent shortages of drugs and medical supplies, long queues, absence of emergency services and poor staff attitudes towards patients, resulting in low utilization of health services (Osei-Atweneboana, Boakye, Gyapong, \& Prichard, 2007).

Turkson (2009) examined the quality of healthcare delivery in a rural district in Ghana and found that generally the quality of healthcare delivery was perceived to be high for most of the indicators such as background characteristics and age. However, poor attitude toward some health workers, long waiting times, high cost of services, inadequate staffing, unclear policy of payment for health services, frequent referrals to hospitals and lack of ambulances at facilities are detrimental to patient 
satisfaction. A comparative study of the University of Ghana and University of Cape Coast Hospitals revealed that communication, empathy, culture, tangibles and priority which was adapted from the SERVQUAL MODEL by Parasuraman et al, (1988) are good predictors of patient satisfaction (Ahenkan, \& Aduo-Adjei, 2017). In-depth interviews with patients show that long waiting-time at the OPD, pharmacy and laboratory negatively affect patients' satisfaction (Ahenkan, \& Aduo-Adjei, 2017).

\section{Research Methodology}

This section presents the methodology employed in the study.

\section{Research Design}

The study which was within the quantitative research approach, employed the cross-sectional design. This type of design is normally considered appropriate for a prevalence of a phenomenon, problem, attitude or issue of concern. As a result, data was gathered at a particular point in time from members of the three study communities who had accessed the CHPS compound for healthcare services (Fraenkel \& Wallen, 2009).

\section{Study area}

The study was conducted in the Wassa Amenfi West District using three rural localities, Bena Nkwanta, Bena and Berekum. The Wassa Amenfi West District is located in the Western Region of Ghana. The three localities were selected for the study because of their high dependence on CHPS compounds for health care. The three localities, with a population of 966, are male dominated with a ratio of 119 males to 100 females in 236 households and 228 houses (Ghana Statistical Service, 2010). The district capital of Wassa Amenfi West where the three localities are situated is Asankrangwa, bounded to the west by Sefwi-Akontombra and Aowin Districts, to the south by Jomoro, Ellembelle and Nzema East Districts, to the East by Prestea Huni Valley and Wassa Amenfi Central Districts.

The district has a total land area of $1,448.56$ square kilometres. The population of Wassa - Amenfi West District was 92,152 representing 3.8 percent of the Western Region's total population. Similarly to the selected localities, the district is male dominated with 51.4 percent of the population being male and 48.6 percent being female. The area was mainly rural, with almost 60 percent of the residents being in rural communities (Ghana Statistical Service, 2010).

\section{Population and Sampling}

The target population was male and female adults aged 18 years or older and resident in the three selected localities whose primary source of health care was the Community Health-Based Planning Service (CHPS). Adults aged 18 years and above were considered for the study because people at these ages were regarded matured and would mostly seek health care on their own, hence, were in positions to give vivid account of their experiences. According to the 2010 Population and Housing Census (GSS, 2016), the population of the three communities was 11,621 from which 151 people were selected to form the sample for the study.

The three communities were together segmented into two approximate equal halves, using the main road that run through them. Subsequently, the systematic random sampling method was used to select houses from the two halves for the study. The first house on the right segment on entering was selected, and every third house in the sequence was selected. The same procedure was adopted for the left segment. In the selected houses, enquires were made about eligible respondents, i.e., aged 18 years or above and who have used the CHPS compound. One eligible person was then administered with the questionnaire in each house. Where there were more than one eligible respondent, the person who often used the CHPS compound was asked to respond to the questionnaire.

\section{Statistical Treatment of Data}

The data was treated through the quantitative approach by the use of frequency and percent of the respondents in various aspects of the questionnaire. Literature was used to enhance the discussion of findings.

\section{Results and Discussion}

This part presents the results of the study. It used tables with interpretations. The tables focused on the indicators that were presented by the subjects under investigation.

\section{Characteristics of Respondents}

The analysis begins with presentation of the characteristics of respondents in terms of locality, age, educational background and marital status. This was important to expose the readers to the fact that respondents were of various backgrounds. 
Table 1: Background Characteristics of Respondents

\begin{tabular}{lcc}
\hline Demographic Factor & Sample & Percent \\
\hline Locality & & 28.5 \\
Berekum & 43 & 47.0 \\
Bena & 71 & 24.5 \\
Bena-Nkwanta & 37 & \\
Age & & 30.5 \\
18-29 & 46 & 53.6 \\
$30-59$ & 81 & 15.9 \\
$60+$ & 24 & \\
Educational Background & & 14.6 \\
No formal Education & 22 & 66.2 \\
Primary/JSS & 100 & 19.2 \\
Secondary/higher & 29 & \\
Sex & & 51.0 \\
Male & 77 & 49.0 \\
Female & 74 & \\
Marital Status & & 33.1 \\
Not married & 50 & 66.9 \\
Married & 101 & \\
\hline
\end{tabular}

Table 2: Responses on attitude toward service providers

\begin{tabular}{|c|c|c|}
\hline Items in the Questionnaire & Response & Percent \\
\hline \multicolumn{3}{|l|}{ Do you like the way you are treated at the facility? } \\
\hline Yes & 126 & 83.4 \\
\hline No & 25 & 16.6 \\
\hline \multicolumn{3}{|c|}{ Do they listen to you during consultation if you have something to say? } \\
\hline Yes & 109 & 72.2 \\
\hline No & 42 & 27.8 \\
\hline \multicolumn{3}{|c|}{ Are your questions answered the way you clearly understand? } \\
\hline Yes & 135 & 89.4 \\
\hline No & 16 & 10.6 \\
\hline \multicolumn{3}{|c|}{ Do you think you are given enough time as you need for your consultation? } \\
\hline Yes & 135 & 67.5 \\
\hline No & 16 & 32.5 \\
\hline \multicolumn{3}{|l|}{ Are you given options on which treatment you prefer? } \\
\hline Yes & 72 & 47.7 \\
\hline No & 79 & 52.3 \\
\hline \multicolumn{3}{|c|}{ Are you told the possible side effects of the tablets/medication given you? } \\
\hline Yes & 66 & 43.7 \\
\hline No & 85 & 65.3 \\
\hline \multicolumn{3}{|c|}{ Do you feel that you are in good hands when you go to the facility? } \\
\hline Yes & 126 & 83.4 \\
\hline No & 25 & 16.6 \\
\hline
\end{tabular}

From Table 1, 28.5\% of the respondents were resident in Berekum, $47.0 \%$ in Bena and $24.5 \%$ in Bena Nkwanta. A $30.5 \%$ of the respondents were in the age group $18-29$ years, $53.6 \%$ were $30-59$ years whilst the remaining $15.9 \%$ were 60 years and older. The majority of the respondents (66.2\%) had primary education, $19.2 \%$ had secondary or higher education whilst $14.6 \%$ had no formal education. With regards to the sex of the respondents, $51.0 \%$ were males, whilst 49.0 percent were females. The table also indicates that $33.1 \%$ of respondents were single while $66.9 \%$ were married. This implies sampling considered the population's backgrounds.

Research Question 1: What are rural community members' perceptions on the attitude of health care providers in CHPS compounds in the Wassa-Amenfi West District?

Table 2 shows the responses given by communities' members who had used CHPS compound to access healthcare on their perception about the attitude of healthcare providers by indicators. 
From Table 2, it is revealed that $83.4 \%$ of the respondents said they liked the way they were treated at the CHPS facilities. A majority of respondents $(72.2 \%)$ revealed that during consultation they were given the chance to express their views; $89.4 \%$ said their questions were answered in a way they clearly understood; $67.5 \%$ said they were given enough time during consultation as compared to $32.5 \%$ who said they were not given enough time. On options for preferred treatment; $47.7 \%$ indicated they were given options whiles $52.3 \%$ said they were not given any option as to the treatment they preferred. Table 2 further reveals that $65.3 \%$ said they were not told the possible side effect of the drugs they were given, whereas $43.7 \%$ said they were told. Another majority $83.4 \%$ of respondents said they felt they were in good hands when they visited the facilities as compared to $16.6 \%$ who disagreed with the statement.

The results in Table 2 revealed that respondents were satisfied with most of the indicators in the table particularly about the way they were treated in the facility, the attention they received from service providers, the way their questions were answered, the time given for consultation as well as the information about the side effects of the medicines. However, majority of respondents were not satisfied with some aspects including options on which treatments they preferred and being told about the side effects of the medicine. This trend of customer dissatisfaction is dangerous as indicated by Turkson (2009) who contended that poor attitude towards health care providers is detrimental.

The finding reveals that healthcare providers have different attitudes towards healthcare seekers. This calls for a relook at the training of health professionals in Ghana. The result also highlights the fact that healthcare seekers have different expectations from healthcare providers. Certainly, respondents' views on health providers' attitudes influenced their appreciations of the services they provide. This concurs with Jenkinson et al. (2002) and Ahmed, Nawaz, Khan, Khan, Rashid and Khan (2011) who espoused that patients' satisfaction are mostly based on caregivers' attitudes towards patients. It similarly agrees with Avortri, Beke and
Abekah-Nkrumah (2011) who identified the feeling of been treated with care and respect as a key predictor of satisfaction; and Turkson (2009) conclusion in his study on quality of healthcare delivery in rural communities in Ghana that, poor attitudes of providers are detrimental to patient satisfaction.

Research Question 2: What perceptions do rural community members have on the quality of medical services provided by CHPS Compound in WassaAmenfi West District?"

The second research question was on respondents' satisfaction with quality of service delivery at CHPS compounds in the Wassa-Amenfi West District. Table 3 (page 93) presents the indicators used to measure patient satisfaction on the quality of health service.

From Table 3 (page 93), $83.3 \%$ of the respondents liked the way they were treated at the CHPS facilities. A majority of respondents (72\%) indicated that they were given the chance to express their views during consultation; $89 \%$ said their questions were answered in a way they clearly understood; and $68 \%$ percent said they were given enough time during consultation. On options for preferred treatment, $52 \%$ said they were not given any option as to the treatment they preferred. Fifty-six point three percent $(56.3 \%)$ said they were not told the possible side effect of the drugs they were given. Also, $56.3 \%$ indicated that patients were not treated equally at the facilities.

Results indicate that majority of respondents were satisfied with various aspects of service delivery. Particularly, they admitted that it doesn't take longer to access the service, the cost of the service is affordable, the drugs are given effectively, there are no long queues at the facility and the visiting of the facility is not stressful. Furthermore, they admitted that the inner and outer environment is conducive for patients, the staff members are friendly and the information about sickness is made readily available. The findings are in line with those of Turkson (2009) who examined the quality of healthcare delivery in a rural district in Ghana and found that generally the quality of healthcare delivery was perceived by recipients to be high. 


\begin{tabular}{|c|c|c|}
\hline Items in the Questionnaire & Response & Percent \\
\hline \multicolumn{3}{|c|}{ Does it take a longer time to access a service at the facility? } \\
\hline Yes & 59 & 39.1 \\
\hline No & 92 & 60.9 \\
\hline \multicolumn{3}{|c|}{ Is the cost of a service affordable? } \\
\hline Yes & 90 & 59.6 \\
\hline No & 61 & 40.4 \\
\hline \multicolumn{3}{|c|}{ Are the drugs given effectively? } \\
\hline Yes & 20 & 79.5 \\
\hline No & 31 & 20.5 \\
\hline \multicolumn{3}{|c|}{ Are there always long queues at the facility? } \\
\hline Yes & 3 & 2.0 \\
\hline No & 148 & 98.0 \\
\hline \multicolumn{3}{|c|}{ Is visiting the facility very stressful? } \\
\hline Yes & 15 & 9.9 \\
\hline No & 136 & 90.1 \\
\hline \multicolumn{3}{|c|}{ Is the inner environment conducive for patients? } \\
\hline Yes & 140 & 92.7 \\
\hline No & 11 & 7.3 \\
\hline \multicolumn{3}{|c|}{ Is the outer environment conducive for patients? } \\
\hline Yes & 144 & 95.4 \\
\hline No & 7 & 4.6 \\
\hline \multicolumn{3}{|c|}{ Is the staff at the facility friendly and respectful? } \\
\hline Yes & 130 & 86.1 \\
\hline No & 21 & 13.9 \\
\hline \multicolumn{3}{|c|}{ Is information about your sickness made readily available to you? } \\
\hline Yes & 108 & 71.5 \\
\hline No & 43 & 28.5 \\
\hline
\end{tabular}

This shows that the CHPS compound is contributing significantly to healthcare delivery in the area. It is significant to note that responses to all other indicators were in the majority positive except the cost of services where $59.6 \%$ of respondents said "yes' and $40.4 \%$ responded "no". Since respondents had different backgrounds, their estimation and calculation of the cost of the services they received varied as it was more personal and subjective. The findings are in line with Turkson (2009) who examined the quality of healthcare delivery in a rural district in Ghana and found that generally the quality of healthcare delivery was perceived by recipients to be high for most of the indicators.

Research Question 3: What are the opinions of rural community members in the Wassa-Amenfi West District on the future use of CHPS compounds?

The third question was on respondents' indications on use of CHPS facility in the future based on their views on the attitudes of service providers and quality of service delivery as reflected in Table 4.

Table 4: Future Use of the Facility

\begin{tabular}{lcc}
\hline \multicolumn{1}{c}{ Item in the Questionnaire } & Response & Percent \\
\hline Will you use the facility again? & 111 & 73.5 \\
Yes & 40 & 26.5 \\
No & & \\
Will you use the facility again if there is an alternative & & \\
available? & 97 & 64.2 \\
Yes & 54 & 35.8 \\
No & & \\
Will you recommend the facility to a relative/ friend? & 108 & 71.5 \\
Yes & 43 & 28.5 \\
No & & \\
\hline
\end{tabular}

From Table 4, 73.5\% of the respondents indicated that they would use the facility and $71.5 \%$ of the respondents were ready to recommend their relatives and friends to the facility. The respondents' 
willingness to use the CHPS compound again largely stemmed from the majority appreciation of the attitudes of service providers and quality of service delivery from the facility. Furthermore, 64.2\%, which is the majority of the respondents were ready to use the facility again if there is an alternative available. This means that their choice to use the facility in the future was not because there were no other alternatives but because they enjoyed the services provided by the facility. Finally, a majority $71.5 \%$ of the respondents were ready to recommend their relatives and friends to the facility. This was a result of a good care extended to customers by the service providers.

The findings from the study show that both provider attitude and quality of service are important factors to care seekers satisfaction and their decision to use healthcare services. Abdul (2017) in this regard, noted that health care seeker satisfaction constitutes is a person's feelings of pleasure or disappointment as a result of comparing a product's perceived performance (or outcome) in relation to his or her expectations. This is supported by Atinga, Abekah-Nkrumah and Domfeh (2011) who identified that timely care is an important factor of care seeker satisfaction. It also similar the finding by Otani, Herrmann, and Kurz (2011) that courtesy, friendliness, care and respectful attitudes toward health care providers are major determinants of clients' satisfaction.

\section{Conclusions and Recommendations}

This part gives conclusions and recommendations pf the study, based on the findings.

\section{Conclusions}

The study came up with the following conclusions:

1. From the findings of the study, it can be concluded that somehow, respondents had positive attitude toward the service provided. This is indicated by the fact that they liked the way they were treated, they were listened to by service providers, their questions were answered clearly and they were given time they needed for consultation. Furthermore, they felt in good hands when they attended the health facility. However, they were they were not given options on which treatment they preferred and were not told about the side effect of the tablets they had taken.

2. Respondents were satisfied with the quality of health services. For instance, they confirmed that it does not take longer to access a service at the facility, the cost is affordable, the drugs are given effectively, there are no long queues, the visit to the facility is not stressful, the inner and outer environment of the facility is conducive, the staff are friendly and the information about their sickness is made readily available.

3. With regard to the use of the facility in the future, it is concluded that respondents were ready to use the facility in the future even if there would be other alternatives. This is because of the best service provided by the service providers.

\section{Recommendations}

Based on the conclusions of the study, it is recommended that the community based health facility should keep on improving the service in order to attract more customers. Furthermore, there is need to give customers options on which treatment they preferred and also they need to be told about the possible side effects of the medications taken.

\section{References}

Abdul, H. R. (2017). Patient satisfaction, hospital image and patient loyalty in West Sulawesi Province. Business and Entrepreneurial Review, Vol. 17. No. 1, 1-14.

Ahmed, I., Nawaz, A., Khan, S., Khan, H., Rashid, M. A., \& Khan, M. H. (2011). Predictors of patient satisfaction. Gomal Journal of Medical Sciences, 9(2) 48 - 52.

Ahenkan, A., \& Aduo-Adjei, K. (2017). Predictors of patient satisfaction with quality of healthcare in university hospitals in Ghana. Hospital Practices and Research, 2(1), 9-14.

Atinga, R. A., Abekah-Nkrumah, G., \& Domfeh, K. A. (2011). Managing healthcare quality in Ghana: A necessity of patient satisfaction. International Journal of Health Care Quality Assurance, 13(2), 112 - 124.

Avortri, G. S., Beke, A., \& Abekah-Nkrumah, G. (2011). Predictors of satisfaction with child birth services in public hospitals in Ghana. International Journal of Healthcare Quality Assurance, 13(2), $112-124$

Al-Abri, R., \& Al-Balushi, A. (2014). Patient satisfaction survey as a tool towards quality 
improvement. Oman Medical Journal, 29(1), 3.

Duggirala, M., Rajendran, C., \& Anantharaman, R. N. (2008). Patient-perceived dimensions of total quality service in healthcare. Benchmarking: An International Journal, 26(3) 68-81.

Escribano-Ferrer, B., Cluzeau, F., Cutler, D., Akufo, C., \& Chalkidou, K. (2016). Quality of health care in Ghana: Mapping of interventions and the way forward. Ghana Medical Journal, 50(4), 238-247.

Esteban O. (2017). Financing healthcare. Our World in Data. https://ourworldindata.o $\mathrm{rg}$ /financing-healthcare

Fraenkel, J. R., \& Wallen, N. E. (2009). How to design and evaluate research in education. New York: McGaw-Hill.

Fisk, R. P., \& Coney, A. K. (1982). Post choice evaluation: An equity theory analysis of consumer satisfaction and dissatisfaction with service choices, In: Hunt, H.K., and Day, L. R. (Eds) Conceptual and Empirical Contributions to Consumer Satisfaction and Dissatisfaction and Complaining Behavior, Bloomington, IN: Indiana University School of Business, 9-16.

Ghana Health Service (GSS) (2005). Ghana living survey 5, with non-farmer household enterprise module. News bulletin 5. Accra: Assembly Press

Ghana Statistical Service (2018). 2010 population and housing census: Summary report of final results. Accessed June, 8, 2018.

Ghana Statiatical Service (GSS) (2016). Consumer price index, 2015. Accra: Assembly Press.

Jenkinson, C., Coulter, A., Bruster, S., Richards, N., \& Chandola, T. (2012). Patients' experiences and satisfaction with health care: Results of a questionnaire study of specific aspects of care. Quality and Safety in Health Care, 11(4), 335-339.

Kathryn, A., M., David A., C., \& Susan, M., G. (2014). The role of clinical and process quality in achieving patient satisfaction in hospitals. Decision Sciences, 35(3), 349-369.
Moutinho, L. (1987). Consumer behaviour in tourism. European Journal of Marketing 21, 5-14.

Nguyen, T. V. F., Anota, A., Brédart, A., Monnier, A., Bosset, J. F., \& Mercier, M. (2014). A longitudinal analysis of patient satisfaction with care and quality of life in ambulatory oncology based on the OUT-PATSAT35 questionnaire. BMC cancer, 14(1), 1-12.

Swan, E. J \& Oliver, L. R., (1989). Consumer perceptions of interpersonal equity and satisfaction in transactions: A field survey approach. Journal of Marketing, 53(2), 2135.

Oliver, R. L. \& DeSarbo, W. S. (1988). Response determinants in satisfaction judgment. Journal of Consumer Research, 14(2), 495507.

Otani, K., Herrmann, P. A., \& Kurz, R. S. (2011). Improving patient satisfaction in hospital care settings. Health Services Management Research, 24(4), 163-169.

Osei-Atweneboana, M. Y., Eng, J. K., Boakye, D. A., Gyapong, J. O., \& Prichard, R. K. (2017). Prevalence and intensity of Onchocerca volvulus infection and efficacy of ivermectin in endemic communities in Ghana: A twophase epidemiological study. The Lancet, 369(9578), 2021-2029.

Reisinger, Y. \& Turner, L. (1997). Tourists satisfaction with hosts: A cultural approach comparing Tai tourists and Australian hosts. Pacific Tourism Review 1(2), 147-159.

Shou-Hsia, Ming-Chin, Tung-Liang (2013). Patient satisfaction with and recommendation of a hospital: effects of interpersonal and technical aspects of hospital care. International journal of Quality Health Care, 15(4) $345-355$

Turkson, P. K. (2009). Perceived quality of healthcare delivery in a rural district of Ghana. Ghana Medical Journal, 43(2) 44 68.

United Nations Development Program (2017). Sustainable Development Goals (SDGs) in Ghana: Why they matter and how we can help. UN Communications Group (UNCG). 
Van den Broek, N. R., \& Graham, W. J. (2009). Quality of care for maternal and newborn health: The neglected agenda.BJOG: An International Journal of Obstetrics \& Gynaecology, (11)6, 18-21.

Woodruff, R. B., Ernest, R. C., \& Jenkins, R. L. (1983). Modeling consumer satisfaction processes using experience-based norms. Journal of Marketing Research, 2(1), 296304.
Yeleduor, V. (2012). The community-based health planning and services (CHPS) and access to health care in the Ashanti Region, Ghana. [Unpublished doctoral dissertation] submitted to the Kwame Nkrumah University of Science and Technology, Kumasi.

Zuure, D. N. (2020). Education for democratic citizenship and human rights in junior high schools in Ghana. Journal of Social Sciences and Humanities, Vol. 6, No. 2, pg $91-103$. ISSN $2381-7771$. 